\title{
Characterization of natural Yemeni zeolites as powder sorbents for ammonium valorization from domestic waste water streams using high rate activated sludge processes
}

\author{
Amel Jmayai, ${ }^{a}$ Mehrez Hermass, ${ }^{\text {a,b* }}{ }^{*}$ Rabeh Alouani, ${ }^{a}$ Jose Luis Cortina ${ }^{\text {b }}$ and \\ Abdesslem Ben Hadj Amaraa
}

\section{Abstract}

BACKGROUND: In this study three natural Yemeni zeolites (NZ1, NZ2 and NZ3) having major minerals such as clinoptilolite and mordenite, were evaluated as low cost sorbents for the removal and recovery of ammonium ions.

RESULTS: The zeolite samples, with $\mathrm{pH}_{\mathrm{PZC}}=9.1 \pm 0.2,7.9 \pm 0.2$ and $7.4 \pm 0.2$ for NZ1, NZ2 and NZ3, respectively, showed high ammonium sorption capacities. At pH 8, for treated waste waters: (i) with low $\mathrm{NH}_{4}^{+}$levels (from 25 to 100 mgNH$/ \mathrm{L}$ ); and (ii) for concentrated $\mathrm{NH}_{4}{ }^{+}$side streams generated from the anaerobic digestion of sewage sludge (from 400 up to $1500 \mathrm{mg} \mathrm{L}^{-1}$ ), maximum loading capacities of 27 to $51 \mathrm{mgNH}_{4} \mathrm{~g}^{-1}$ were measured for the studied zeolites. Measured sorption isotherms, in the concentration range 0.05 to $5 \mathrm{~g} \mathrm{~L}^{-1}$, were well described by the Langmuir isotherm. The ammonium sorption kinetics was controlled by particle diffusion and was well described by both the homogeneous diffusion (HPDM) and shell progressive (SPM) models.

CONCLUSION: Comparison of the equilibrium data with results for natural and synthetic zeolites demonstrate the higher performance of the studied zeolites providing low residual ammonium values $<1 \mathrm{mgNH}_{4} \mathrm{~g}^{-1}$ and $<10 \mathrm{mgNH}_{4} \mathrm{~g}^{-1}$ when treating both diluted and concentrated- $\mathrm{NH}_{4}{ }^{+}$streams, respectively.

(C) 2017 Society of Chemical Industry

Supporting information may be found in the online version of this article.

Keywords: natural Yemeni zeolite; clinoptilolite; mordenite; ammonium recovery; high rate activated sludge

\section{INTRODUCTION}

Natural zeolites have attracted significant interest over the last two decades especially with regard to their capacity to eliminate or reduce water pollution problems. Nitrogen $(\mathrm{N})$ is the primary element of plant and animal proteins and is essential to all life forms. ${ }^{1}$ However, high concentrations of $\mathrm{N}$ in surface and ground water cause high oxygen demand and can lead to eutrophication. ${ }^{2}$ Ammonium $\left(\mathrm{NH}_{4}{ }^{+}\right)$with $\mathrm{NO}_{3}{ }^{-} / \mathrm{NO}_{2}$ are the main inorganic ionic form of $\mathrm{N}$ present in domestic and industrial waste waters but it is also generated from organic $N$ compounds. ${ }^{3}$ In these types of effluents, the $\mathrm{N}$ forms are removed traditionally by biological methods ${ }^{4}$ whereby the $\mathrm{N}$ is converted to biomass or is transformed into $\mathrm{N}_{2}(\mathrm{~g})$, although when biomass is anaerobically digested to produce bio-methane, $\mathrm{N}$ is again re-mineralized to $\mathrm{NH}_{4}{ }^{+} .{ }^{5}$ However, new valorization technologies for the removal and recovery of ammonium are needed to overcome problems that could be encountered in: (a) the implementation of high rate activated sludge (HRAS) or up-concentration schemes promoting the enhancement of energy recovery by anaerobic digestion, producing treated effluents with high ammonium contents (up to $100 \mathrm{mg}$ $\left.\mathrm{L}^{-1}\right) ; 6,7$ (b) new stringent regulation of $\mathrm{N}$ levels on the discharges of treated water (e.g. values of $\mathrm{NH}_{4}{ }^{+}$below $1 \mathrm{mg} \mathrm{L}^{-1}$ ); or (c) the need to recover nitrogen on account of its high nutrient value. Among the newer valorization strategies used is the recovery of ammonium as struvite; however, only a small fraction of the total ammonium load is recovered (c. 10\%). ${ }^{8,9}$ Alternative recovery strategies employ the use of striping and sorption processes, however increasing effort is being used on the integration of membrane processes. ${ }^{10,11}$ The use of conventional synthetic polymeric sorbents (e.g. cation exchange resins) and polymeric membranes based technologies has limited applications mainly on account of the fouling encountered due to the high content of total suspended solids and

* Correspondence to: Mehrez Hermassi,Departamentd'Enginyeria Química, Universitat Politècnica de Catalunya, Av. Diagonal 647, 08028 Barcelona, Spain. Email: hermassi.mehrez@gmail.com

a Department of Physics, UR05/13-01: Laboratory of Physics of Lamellar Hybrid Materials and Nanomaterials, Faculty of Science of Bizerte, 7021 Zarzouna, Tunisia

b Department of Chemical Engineering, Universitat Politècnica de Catalunya-Barcelona Tech(UPC), 08028Barcelona, Spain 
dissolved organic matter present in waste waters. ${ }^{11,13}$ Inorganic materials like ceramic membranes of zeolites represent a suitable option for promoting ammonium recovery mainly on account of their favorable physico-chemical properties. ${ }^{14}$ However, there is a lack of study on whether zeolites could be integrated using standard sorption technologies like bed columns and granular forms ${ }^{15,16}$ or whether they could be used as powdered forms in hybrid sorption-filtration technological approaches. ${ }^{17-19}$

Zeolite, which is a naturally occurring hydrated aluminosilicate mineral, mainly consists of a three-dimensional framework bearing tetrahedral structures of $\mathrm{SiO}_{4}$ and $\mathrm{Al}_{2} \mathrm{O} .^{20,21}$ The cages and channels within the three-dimensional framework of the zeolites are occupied by water, alkali $\left(\mathrm{Na}^{+}, \mathrm{K}^{+}\right)$and alkaline earth cations $\left(\mathrm{Ca}^{2+}, \mathrm{Mg}^{2+}, \mathrm{Ba}^{2+}\right) \cdot{ }^{22-24}$ As these ion-exchangeable cations are present in hydrated forms in the zeolite cavities their exchange leads to the reformation of the pore structure. ${ }^{23-25}$ Natural zeolites are very effective in the removal of ammonium, which occurs by exchange with $\mathrm{Na}^{+}, \mathrm{K}^{+}, \mathrm{Ca}^{2+}$ and $\mathrm{Mg}^{2+}$ as has been demonstrated in numerous studies of different mineral deposits. ${ }^{26,27}$ The purification of waters and the treatment of industrial and urban waste waters have been the main fields of application of natural zeolitic materials. ${ }^{28-30}$ From the large list of zeolite deposits identified and reported the most widely studied are those from Turkey, Slovakia, Australia, Greece, Iran and Italy. ${ }^{31-33}$ However, limited studies could be found in relation to the Yemen which has huge reserves of zeolitic tuffs deposits which could have potential industrial and environmental applications.

Thus the objective of this study is two-fold: (a) to characterize mineralogically and chemically three different selected samples of zeolitic material obtained from three different deposits in Yemen, the selection was performed, inside a collaborative project between two geological research groups of Yemen and Tunisia; and (b) to determine the ammonium sorption properties of the zeolitic materials in powdered form for their ultimate use in the recovery of ammonium from treated waste waters by evaluating their equilibrium and kinetic parameters. Synthetic and real ammonium solutions were used for this characterization. Treated waste water used in the present study was collected from El Prat Waste Water Treatment Plant (Barcelona, Spain) and was found to contain common cations like calcium ( $200 \mathrm{mg} \mathrm{L}^{-1}$ ), magnesium $\left(74 \mathrm{mg} \mathrm{L}^{-1}\right)$, sodium ( $\left.280 \mathrm{mg} \mathrm{L}^{-1}\right)$ and potassium $\left(38 \mathrm{mg} \mathrm{L}^{-1}\right)$ and anions like chloride $\left(1180 \mathrm{mg} \mathrm{L}^{-1}\right)$, phosphate $\left(33 \mathrm{mg} \mathrm{L}^{-1}\right)$, and sulfate $\left(45 \mathrm{mg} \mathrm{L}^{-1}\right)$. Such competing ions may affect $\mathrm{NH}_{4}{ }^{+}$sorption. Finally, a detailed comparison of the properties of Yemeni zeolites was made with those of zeolites reported in the literature and widely used for industrial and environmental applications, especially for ammonium removal technology for new waste water treatment processes incorporating high rate activated sludge schemes.

\section{MATERIALS AND METHODS}

\section{Yemen natural zeolites: sampling locations}

Natural zeolites of good quality occurring in altered volcanic tuffs were identified in several areas of Yemen. The main reserves of high quality zeolite deposits are located in three provinces: Taiz, Ibb and Dhamar according to the Yemen Geological Survey and Mineral Resources Board. ${ }^{34}$ Samples used in the present study were collected from three different locations: Jebel Hilen Maireb (Natural zeolite sample 1: NZ1), Jebel Hadad (NZ2) and Jebel el Hard (NZ3). Location details of the sample points are given in Fig. 1.

\section{Zeolites physico-chemical characterization}

Determination of crystal structure and the mineralogy of the zeolites was performed using X-ray diffraction (XRPD) D8 Bruker with Cu-k $\square(\square=0,154)$ radiation operating at $40 \mathrm{kV}$ and $40 \mathrm{~mA}$. The chemical composition of the samples was analyzed by X-ray fluorescence (ARL 9900 X-ray). Sample morphology and surface chemical composition were analyzed by field emission scanning electron microscope (FESEM) (JEOL JSM-7001F) coupled to an energy dispersive spectroscopy (EDS) system (Oxford Instruments X-Max). Each FESEM image is originated from a different area of the sample, in order to ensure the homogeneity of the zeolitic structure. Qualitative and quantitative mineralogical characteriza- tion was carried out by means of X-ray powder diffraction patterns using a PanalyticalX'Pert Pro diffractometer equipped with a RTMS detector. Before all analyses, samples were ground and sieved by a particle size siever and thoroughly washed with de-ionized water to remove dust and traces of soluble particles.

The point of zero charge (PZC) was determined by the $\mathrm{pH}$ drift method. ${ }^{34} \mathrm{~A}$ fixed amount of $0.2 \mathrm{~g}$ of sample zeolite was equilibrated in $50 \mathrm{~mL}$ of deionized water, $0.01 \mathrm{~mol} \mathrm{~L}^{-1}$ and $0.05 \mathrm{~mol}$ $\mathrm{L}^{-1} \mathrm{NaCl}$ solutions ( $\mathrm{pH}$ from 2 to 12 ) for $24 \mathrm{~h}$ under gentle agitation and at $22 \pm 1^{\circ} \mathrm{C}$. The final $\mathrm{pH}$ was measured and the PZC was determined as the $\mathrm{pH}$ at which the addition of the sample did not induce a shift in the $\mathrm{pH}$. The common intersection point (CIP) method was also used. ${ }^{35}$ PZC experiments were performed in triplicate and the average data reported.

\section{Ammonium equilibrium and kinetic batch studies}

Batch equilibrium sorption experiments were carried out using standard batch methodology described elsewhere. ${ }^{36}$ Fixed volumes $(25 \mathrm{~mL})$ of prepared ammonium $(\mathrm{N})$ aqueous solutions in polyethylene tubes were used. They were shaken overnight with weighed amounts of dry zeolitic samples (particle size $<200$ $\square \mathrm{m}$ ) using a continuous rotary mixer. Three different types of experi- ment were conducted: (a) sorption capacity as a function of ammo- nium concentration: in which $0.2 \mathrm{~g}$ of zeolite samples were added to varying ammonium (10-2000 mg-N/L) aqueous solutions main- tained at fixed $\mathrm{pH}$ using $\mathrm{pH}$ adjustment to achieve values of

$8.0 \pm 0.2$; (b) sorption capacity as a function of equilibrium $\mathrm{pH}$ range: in which $0.2 \mathrm{~g}$ of NZ sample was added to fixed ammonium (600 mg-N/L) aqueous solutions and adjusting $\mathrm{pH}$ from 7 to 10 (using $0.1 \mathrm{~mol} \mathrm{~L}^{-1} \mathrm{HCl} / \mathrm{NaOH}$ ); and (c) finally sorption capacity as a function of the amount of natural zeolite at a constant ammonium concentration (from 0.2 to $1 \mathrm{~g}$ in $25 \mathrm{~mL}$ of waste water solution). In all experimental conditions, samples were shaken for at least $24 \mathrm{~h}$ at $22^{\circ} \mathrm{C}$

Batch kinetic sorption experiments were performed by adding $0.2 \mathrm{~g}$ of NZs in solutions containing $864 \mathrm{mg}-\mathrm{NH}_{4} \mathrm{~L}^{-1}$ and shaken at $200 \mathrm{rpm}$. Tubes were withdrawn sequentially at given time intervals. All tests were performed in triplicate at $300 \mathrm{rpm}$ and room temperature $\left(22 \pm 1^{\circ} \mathrm{C}\right)$, and the average data reported. The samples were centrifuged for $10 \mathrm{~min}$ and then filtered using $0.45 \square \mathrm{m}$ cellulose nitrate membrane. The total concentration of ammonium ions in the initial and in the remaining aqueous solution was determined.

\section{Ammonium batch desorption studies}

Samples of NZs (particle size $<200 \square \mathrm{m}$ ) were saturated in 25 $\mathrm{mL}$ of solution containing $630 \mathrm{mg}-\mathrm{NH}_{4} \mathrm{~L}^{-1}$ at $300 \mathrm{rpm}$ for $24 \mathrm{~h}$. NZ sam-

ples

were separate

d by

filtration

and

rinsed

several

times

with

deionize

d water

for the

desorpti

on

experim ent. The desorpti on 


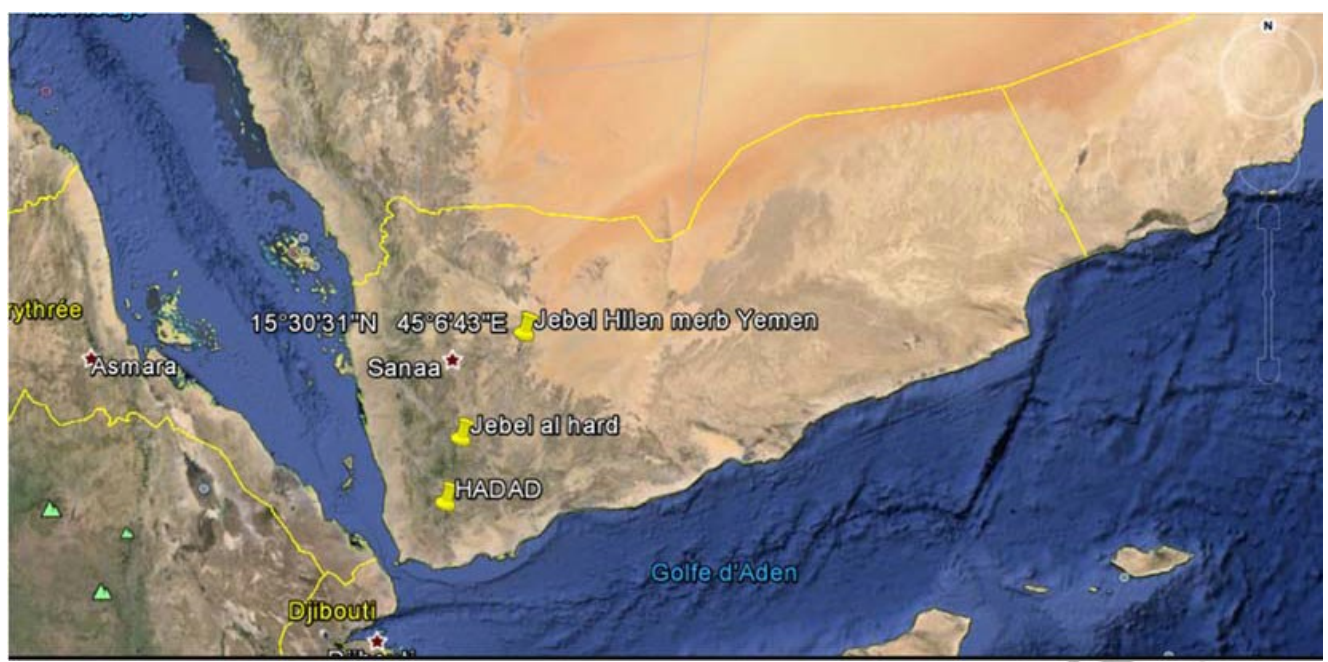

Figure 1. Geographical location of zeolite deposits used in the present study: Jebel Hilen Maireb (Natural zeolite sample 1: (NZ1), Hadad (NZ2) and Jebel al Hard (NZ3).

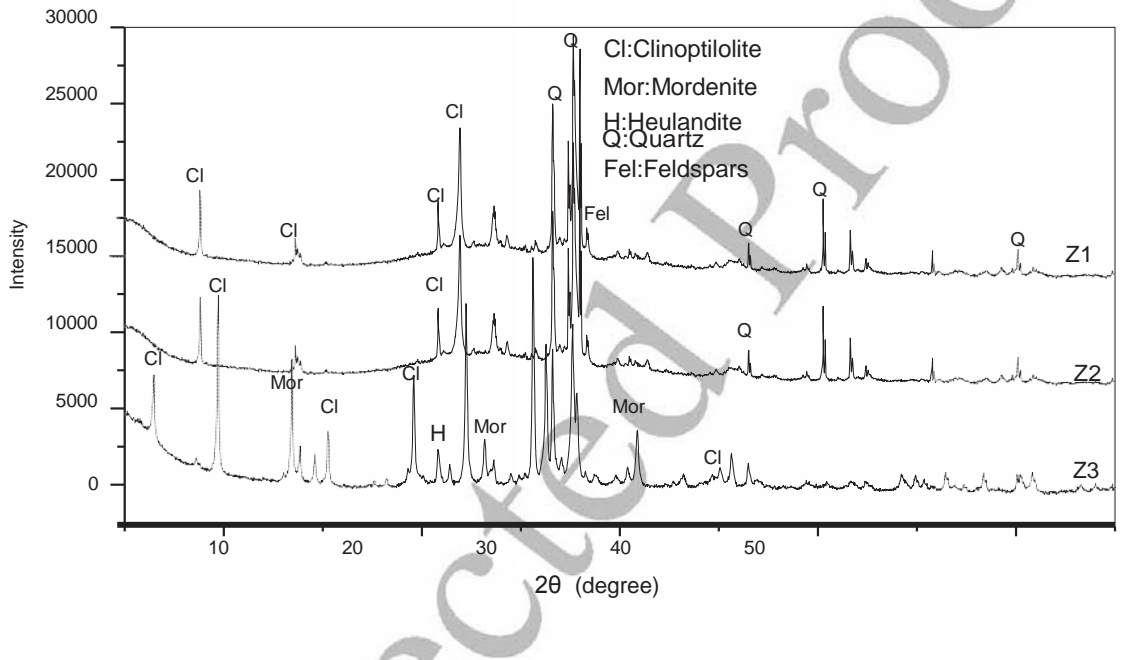

Figure 2. XRD patterns of Yemeni raw natural zeolites NZ1, NZ2 and NZ3 (Cl (clinoptilolite), Mor (mordénite), H (heulandite), Q(quart), Fel(feldspars)).

studies were performed by adding $0.2 \mathrm{~g}$ of the saturated zeolite into $25 \mathrm{~mL}$ of elution solution at $300 \mathrm{rpm}$ for $20 \mathrm{~h}$. $0.02 \mathrm{~mol} \mathrm{~L}^{-1}$ $\mathrm{NaOH}, 0.1 \mathrm{~mol} \mathrm{~L}^{-1} \mathrm{NaCl}, 0.02 \mathrm{~mol} \mathrm{~L}^{-1} \mathrm{NaOH}$ and $0.1 \mathrm{~mol} \mathrm{~L}^{-1} \mathrm{NaCl}$ solutions were evaluated as desorbing solvents. After elution and proper conversion to the $\mathrm{Na}$ form the zeolite was washed water to remove the excess of the regenerant solution. Tests were performed in triplicate at $22 \pm 1{ }^{\circ} \mathrm{C}$, and average data reported. Anions and cation concentrations were determined by ionic chromatography (Dionex ICS-1100 and ICS-1000).

Loaded and desorbed zeolite samples were analyzed by XRD and samples were dried, avoiding high temperatures to minimize the potential losses of ammonium and ammonia.

\section{Data treatment procedures}

\section{Ammonium sorption isotherms}

Ammonium sorption values $\left(q_{e}\right)$ were calculated from the batch experiment results using Equation (2):

$$
q_{e}=\left(c_{o}-C_{e}\right) \times \frac{v}{w}
$$

where $C_{0}\left(\mathrm{mg} \mathrm{L}^{-1}\right)$ and $C_{\mathrm{e}}\left(\mathrm{mg} \mathrm{L}^{-1}\right)$ represents the initial and equilibrium ammonium concentration, respectively; $v(L)$ is the aqueous solution volume and $w(\mathrm{~g})$ is the mass of zeolite. The ammonium equilibrium sorption was evaluated according to the Langmuir isotherm using Equation (3):

$$
q e=\frac{K_{L} q_{m} C_{e}}{1+K_{L} C_{e}}
$$

where $q_{m}\left(\mathrm{mg} \mathrm{g}^{-1}\right)$ is the maximum sorption capacity and $K_{L}$ $\left(\mathrm{L} \mathrm{mg}^{-1}\right)$ is the Langmuir sorption equilibrium constant.

\section{Ammoniumsorptionkinetics}

The homogeneous diffusion (HPDM) and shell progressive model (SPM) were selected to describe the ammonium extraction kinetics by NZs. In the HDM model zeolite particles are considered as a quasi-homogeneous media and the sorption diffusion rate controlling step on the spherical particles leads to:

$$
\text { (i) If particle diffusion } \mathrm{Dp}\left(\mathrm{m}^{2} \mathrm{~s}^{-1}\right)
$$

$$
\text { controls the sorption rate: }-\ln \left(1-X(t)^{2}\right)=2 \square D_{p} t
$$




$$
\begin{aligned}
& \text { (ii) If liquid film diffusion Df }\left(\mathrm{m}^{2} \mathrm{~s}^{-1}\right) \\
& \text { controls the sorption rate: }-\ln (1-X(t))=\frac{D_{f} C}{h r C_{z}} t
\end{aligned}
$$

where $X(t)$ is the fractional attainment of sorption equilibrium $\left(q_{t} / q_{e}\right)$ on the zeolite phase at time $t, C_{s}$ and $C_{r}\left(\mathrm{mg} \mathrm{kg}^{-1}\right)$ are the concentrations of solute in solution and in the zeolite, respectively; $r$ is the average radius of zeolite particles $\left(4 \times 10^{-4} \mathrm{~m}\right), t$ is the contact time (s); and $h$ is the thickness of film around the zeolite particle $\left(1 \times 10^{-5} \mathrm{~m}\right.$ for poorly stirred solution).

The SPM describes the sorption process by a concentration profile of the solution containing ammonium ions advancing into a spherical particle partially saturated. ${ }^{37}$ The removal mechanism involves diffusion of ammonium from the aqueous solution into the zeolite phase through a number of possible resistances. The ammonium species originally in the solution phase must diffuse across the liquid film surrounding the zeolite particle, transfer across the solution particle interface, diffuse into the bulk of the particle and possibly interact with negative charged sites on the zeolite particles. The sorption rate controlling steps on the zeolite particles leads to:

$$
\text { (a) For fluid film diffusion: } X(t)=\frac{3 C_{A 0} K_{F}}{a_{S} C_{S 0}} t
$$

(b) For particle diffusion:

$$
-3(1-X(t))^{\underline{2}}-2 X(t)=\frac{6 D_{e} C_{A 0}}{a^{8} C_{s 0}} t
$$

Where $q_{t}$ and $q_{e}$ are zeolite ammonium loading at time $t$ and when equilibrium is attained $\left(\mathrm{mg} \mathrm{g}^{-1}\right)$, respectively.

All experimental data were treated graphically and compared with all fractional attainment of equilibrium functions $(F(X)=f(t))$ (Equations (4)-(8))

\section{RESULTSANDDISCUSSION}

\section{Zeolite samples characterization}

$X$ ray diffraction (XRD) patterns of $\mathrm{NZ}$ samples are shown in Fig. 2. Clinoptilolite and mordenite were found to be the major components of NZ1 and NZ2, but small amounts of other crystalline phases like quartz, feldspars and unaltered glass were also detected. In the case of NZ3 in addition to clinoptilolite, mordenite and some small amounts of heulandites, the presence of quartz and feldspars were also detected.

XRF analysis, of the samples as summarized in Table 1 revealed the predominance of $\mathrm{SiO}_{2}$ and $\mathrm{Al}_{2} \mathrm{O}_{3}$ and to a lesser extent, appears when the ratio $\mathrm{SiO}_{2} / \mathrm{Al}_{2} \mathrm{O}_{3}$ is between 4.3 and 6.5 and the ratio $\left(\mathrm{K}_{2} \mathrm{O}+\mathrm{Na}_{2} \mathrm{O}\right) /(\mathrm{MgO}+\mathrm{CaO})$ ranges from 1.5 to $0.8 .^{38}$ The high overall $\mathrm{nSi} / \mathrm{nAl}>4$ ratio in the samples can be attributed to the existence of significant proportions of feldspars, quartz and unaltered glass. ${ }^{38}$ Generally, major chemical components $\left(\mathrm{SiO}_{2}\right.$ and $\mathrm{Al}_{2} \mathrm{O}_{3}$ ) showed small differences when compared with other natural zeolites from different deposits (Table 1 ) and this may be due to their different geological formation environment.

It should be mentioned, especially for NZ3, that it has high contents of $\mathrm{Fe}_{2} \mathrm{O}_{3}(7.8 \%)$ and $\mathrm{CaO}(4.4 \%)$ in comparison with NZ1 and NZ2 as well as in comparison with the other natural zeolites, as can be seen in Table 1. The presence of the two minerals can be an added benefit for the zeolite for waste water treatments as they can provide better phosphate removal potential. In the presence of Ca (II), phosphate removal is promoted by the formation of calcium phosphate minerals, 15,40 and in the presence of iron oxides, phosphate sorption is fostered by complexation with < $\mathrm{FeOH}$ surface groups.

The acid-base properties were determined using the PZC method. From the analysis of the variation of $\Delta \mathrm{pH}$ with $\mathrm{pH}$, as can be seen in Fig. S1 (Supporting information), values of $9.1 \pm 0.3$, $7.9 \pm 0.2$ and $7.4 \pm 0.2$ for NZ1, NZ2 and NZ3, respectively, were determined. Values were related to the measured ammonium exchange capacities and results shown that NZ3 with the lowest

value shows the highest sorption capacity. Values of the $\mathrm{pH}$ of treated ammonium model samples had values of $\mathrm{pH}$ covering the range of $\mathrm{pH}_{\mathrm{PzC}}$. Then under these conditions zeolites with the low-

est point of zero charge will provide the highest sorption capacity for cations such as ammonium. Observed fluctuations on $\Delta \mathrm{pH}$ versus $\mathrm{pH}$ data are attributed to the presence of minerals with basic

properties such as calcite. These are present in minor quantities and then from sample to sample small variations are expected. Although little PZC data of natural zeolites could be found in the literature, values of 6.5 to 7.5 were reported by Kosmulski, ${ }^{44}$ while data for clays, the closest mineral family, showed values from 8.5 up to more acidic values of $5.1 .{ }^{45}$ Guaya et al. ${ }^{15,46}$ reported values of 5.5 for a natural clinoptinolite in the sodium form and $4.5 \pm 0.2$ when impreganted with hydrated aluminium oxide or $6.4 \pm 0.4$ when impregnated with hydrated ferric oxide, as described also by Alshamare et al. ${ }^{47}$ Values of $\mathrm{pH}_{\mathrm{PzC}}$.

$61 \mathrm{Fe}_{2} \mathrm{O}_{3}$ and $\mathrm{CaO}$, although in sample NZ3 their contribution is as

62 important as the $\mathrm{Al}_{2} \mathrm{O}_{3}$ in NZ1 and NZ2. The formation of zeolite a

network

of

crystal

clusters

for the

NZ

(support

ing

informat

ion, Fig.

S2) with

homoge

neous

crystal

size 
distribution. The images showed a few smaller particles with spherical shapes and mostly large particles and agglomerates with irregular shapes. The difference in the morphology as evident at the edges is probably due the way the sample was processed (e.g. milling conditions may result in small differences in appearance). It is observed that the clinoptilolite crystal phase has characteristi- cally plate-like morphology (Fig. S2) with large cavities and entries to the channels inside the zeolite framework, and mordenite phase has thinner sheets in accordance with the zeolites morphology. ${ }^{48}$

The FESEM-EDX analysis revealed the presence of $\mathrm{O}, \mathrm{Na}, \mathrm{Mg}, \mathrm{Al}, \mathrm{Si}, \mathrm{K}, \mathrm{Ca}$ and $\mathrm{Fe}$ as the main elements in the surface composition of the zeolites (Table S1 (supporting information)). Table S1 also reveals the chemical composition of different natural zeolites. Sim- ilar values were obtained for the major elements $(\mathrm{O}, \mathrm{Al}, \mathrm{Si})$ which are the main building blocks of zeolite structure; but differences were attributed to exchangeable cations ( $\mathrm{K}, \mathrm{Na}$, $\mathrm{Ca}$ ) and for the Fe content. As described earlier from the XRF analysis, NZ3 showed a higher content of Fe and $\mathrm{Ca}$ but the values were found comparable with those from a study with a zeolite from Yemen (Table S1).

104

105

106

107

108

109

110

111

112

113

114

115

116

117

118

119

120

121

122

123

124 
Table 1. Chemical composition (\%) (w/w) of raw natural zeolites determined by XRF and data on natural zeolites from the main world deposits in Turkey, Iran, China, Australia, Greece, Chile and Yemen

\begin{tabular}{|c|c|c|c|c|c|c|c|c|c|c|}
\hline & NZ1 & NZ2 & NZ3 & $\begin{array}{c}\text { Turkish zeolite } \\
\text { [31] }\end{array}$ & $\begin{array}{c}\text { Iranian zeolite } \\
\text { [32] }\end{array}$ & $\begin{array}{c}\text { Chinese zeolite } \\
\text { [39] }\end{array}$ & $\begin{array}{c}\text { Australian zeolite } \\
\text { [33] }\end{array}$ & $\begin{array}{c}\text { Chilean zeolite } \\
\text { [19] }\end{array}$ & $\begin{array}{c}\text { Greek zeolite } \\
{[40]}\end{array}$ & $\begin{array}{c}\text { Yemeni NZ } \\
\text { [41] }\end{array}$ \\
\hline $\mathrm{SiO}_{2}$ & 62 & 68 & 68 & 70.9 & 70.0 & 66.4 & 70.4 & 67.0 & 68.3 & 69.9 \\
\hline $\mathrm{Al}_{2} \mathrm{O}_{3}$ & 10.2 & 11.1 & 9.2 & 12.4 & 10.5 & 12.2 & 12.9 & 13.0 & 13.2 & 11.8 \\
\hline $\mathrm{Fe}_{2} \mathrm{O}_{3}$ & 1.9 & 2.0 & 7.8 & 1.2 & 0.5 & 1.0 & 1.4 & 2.0 & 1.4 & 2.4 \\
\hline $\mathrm{CaO}$ & 3.9 & 2.4 & 4.4 & 2.5 & 0.2 & 3.2 & 3.3 & 3.2 & 0.8 & 2.4 \\
\hline $\mathrm{MgO}$ & 0.5 & 0.8 & 0.5 & 0.8 & - & 1.0 & 1.1 & 0.7 & 1.2 & 0.2 \\
\hline $\mathrm{K}_{2} \mathrm{O}$ & 1.1 & 1.1 & 0.5 & 4.5 & 4.9 & 1.4 & 1.6 & 0.5 & 1.7 & 3.7 \\
\hline $\mathrm{Na}_{2} \mathrm{O}$ & 0.3 & 0.4 & 0.3 & 0.3 & 2.9 & 0.7 & 1.2 & 2.6 & 4.1 & 1.1 \\
\hline
\end{tabular}

Table 2. Influence of $\mathrm{pH}$ on the ammonium sorption capacity for solutions having an initial concentration of $864 \mathrm{mgN}-\mathrm{NH}_{4} \mathrm{~L}^{-1}$ and a phase ratio of $0.2 \mathrm{~g} \mathrm{NZ}$ in $25 \mathrm{~mL}$ of aqueous solution

\begin{tabular}{|lccc|} 
& \multicolumn{3}{c|}{$q_{e}\left(\mathrm{mgN} \mathrm{NH}_{4} \mathrm{~g}^{-1}\right)$} \\
\cline { 2 - 4 } & $\mathrm{pH}=7.6 \pm 0.1$ & $\mathrm{pH}=8.0 \pm 0.2$ & $\mathrm{pH}=9.0 \pm 0.1$ \\
\hline $\mathbf{N Z 1}\left(\mathrm{pH}_{\mathrm{PZC}} 9.1 \pm 0.3\right)$ & $19.4 \pm 0.6$ & $23.4 \pm 0.8$ & $15.7 \pm 0.9$ \\
$\mathbf{N Z 2}\left(\mathrm{pH}_{\mathrm{PZC}} 7.9 \pm 0.2\right)$ & $23.9 \pm 0.8$ & $27.4 \pm 0.9$ & $26.7 \pm 1.2$ \\
$\mathbf{N Z 3}\left(\mathrm{pH}_{\mathrm{PZC}} 7.4 \pm 0.2\right)$ & $35.1 \pm 1.1$ & $39.6 \pm 1.2$ & $32.7 \pm 1.2$ \\
\hline
\end{tabular}

\section{Ammonium sorption capacity: $\mathrm{pH}$ dependence and equilibrium isotherms}

Although the removal of ammonium is mainly driven by an ion exchange process, the acid-base properties of both ammonium and the zeolite surface can be determined by identifying the optimum $\mathrm{pH}$ of the aqueous medium; thus the dependence on aqueous $\mathrm{pH}$ is an important factor controlling ammonium sorption. ${ }^{49}$ Then sorption capacities of the NZ samples were determined in the expected $\mathrm{pH}$ values of treated urban waste waters ranging from 7 to 9 and the results are summarized in Table 2. Ammonium sorption capacities of each zeolite reached the highest values at $\mathrm{pH} 8$ and then, as is expected from its acid-base properties, started to decrease with further increase in $\mathrm{pH}$ as it is transformed to a non-protonated form $\left(\mathrm{NH}_{3}\right)$. The $q_{e}-\mathrm{pH}$ functions showed constant values between $\mathrm{pH} 4$ to 9 as described previously by Guaya et al., ${ }^{15,43}$ Alshameri et al. ${ }^{41}$ and Moussavi et al. ${ }^{49}$ The highest sorption values of three zeolite samples were attained at $\mathrm{pH}$ values approaching the PZC. In comparison, it was found that the maximum sorption values of the three zeolites ranged from 33 to 40 $\mathrm{mgN}-\mathrm{NH}_{4} \mathrm{~g}^{-1}$ and such differences could be associated with the different composition of the exchangeable ions on the zeolites $(\mathrm{K}, \mathrm{Na}, \mathrm{Mg}$, and $\mathrm{Ca})$. For waste streams with $\mathrm{pH}$ values below 6 , while from the chemical speciation point of view ammonium will be the dominant species for inorganic ammonium forms from the acid-base properties of the zeolite structure the exchange sites will be partially dissociated. However, results in Table 3 show that the weight of the chemical speciation in solution plays a dominant role in the ion-exchange reaction.

Analysis of the sorption capacity in aqueous phase (data not reported) confirms the release of $\mathrm{Na}^{+}$and, in minor degree, of $\mathrm{K}^{+}, \mathrm{Mg}^{2+}$ and $\mathrm{Ca}^{2+}$. EDAX data revealed also the reduction in content of these cations in the ammonium loaded zeolites.

Thus, the sorption of ammonium by the natural zeolites could be
Table 3. Isotherm parameters for ammonium sorption by natural zeolites NZ1, NZ2 and NZ3 for a phase ratio of $0.2 \mathrm{~g} \mathrm{NZ}$ and $25 \mathrm{~mL}$ of aqueous solution and constant temperature of $22 \pm 1{ }^{\circ} \mathrm{C}$

\begin{tabular}{|ccccccc|} 
& \multicolumn{3}{c}{ Langmuir } & & \multicolumn{3}{c|}{ Freundich } \\
\cline { 5 - 8 } & $q_{m}$ & $K_{L}$ & $\mathrm{R}^{2}$ & $K_{F}$ & $n$ & $\mathrm{R}^{2}$ \\
\hline $\mathrm{NZ1}$ & $27.4 \pm 2$ & 0.0007 & 0.98 & 0.063 & 1.2 & 0.92 \\
$\mathrm{NZ2}$ & $32.2 \pm 2$ & 0.001 & 0.98 & 0.31 & 1.7 & 0.92 \\
$\mathrm{NZ3}$ & $51.8 \pm 4$ & 0.0036 & 0.99 & 0.68 & 1.6 & 0.95 \\
\hline
\end{tabular}

(i) Ion exchange reaction with $\mathrm{M}^{+}$from the zeolite sites as it is described by Equation (10):

$$
\mathrm{Z}^{-} \mathrm{M}^{+}+\mathrm{NH}_{4}^{+}-\mathrm{M}^{+}+\mathrm{Z}-\mathrm{NH}_{4}^{+}
$$

described by the combination of two main processes: ${ }^{50}$ 


$$
\mathrm{NH}^{+} \leftrightarrow \mathrm{H}^{+}+\mathrm{NH}_{3} \quad \log \mathrm{K}_{\mathrm{a}}=-9.3
$$

According to Equation (11), $\mathrm{NH}_{4}^{+} / \mathrm{NH}_{3}$ equilibrium in solution is $\mathrm{pH}$ dependent and thus only the ionized form can be removed from solution by ion exchange. At pH 8 and below total ammo- nium is substantially present in the ionized form, therefore, it is rea- sonable to assume that these conditions would favor the removal process.

Equilibrium sorption isotherms with ammonium solutions cover- ing the ammonia concentration range expected in effluents from the high rate activated sludge stage (25 to $100 \mathrm{mgNH}_{4}{ }^{+} \mathrm{L}^{-1}$ ) and inside streams of sludge anaerobic digestion ( 400 to $1600 \mathrm{mgNH}_{4}{ }^{+} \mathrm{L}^{-1}$ ) are shown in Fig. 3. The ammonium sorption data are well described by the Langmuir isotherm $\left(R^{2} \geq 0.98\right)$ while Freundlich isotherm $\left(R^{2} \leq 0.95\right)$ (Table 3 and Fig. 3) provides a good descrip- tion only at the lower concentration ranges. Therefore, monolayer and homogenous sorption or/and ion exchange at specific and equal affinity sites available on the zeolites surface is supposed to occur. A favorable sorption is revealed by the values of $K_{L}$ (from 0.0007 to 0.0036 ). ${ }^{28}$ The maximum sorption capacities was found to be $27.4 \pm 2 \mathrm{mg}^{-\mathrm{N} \mathrm{g}^{-1}}, 32.2 \pm 2 \mathrm{mg}^{-\mathrm{N} \mathrm{g}^{-1}}$ and $51.8 \pm 4 \mathrm{mg}^{-\mathrm{N} \mathrm{g}^{-1}}$ for NZ1, NZ2 and NZ3, respectively.

XRD patterns of the NZs after sorption (Fig. S3) showed that the differences could be observed only in the intensity of reflexions, but no changes were observed with respect to their position. 


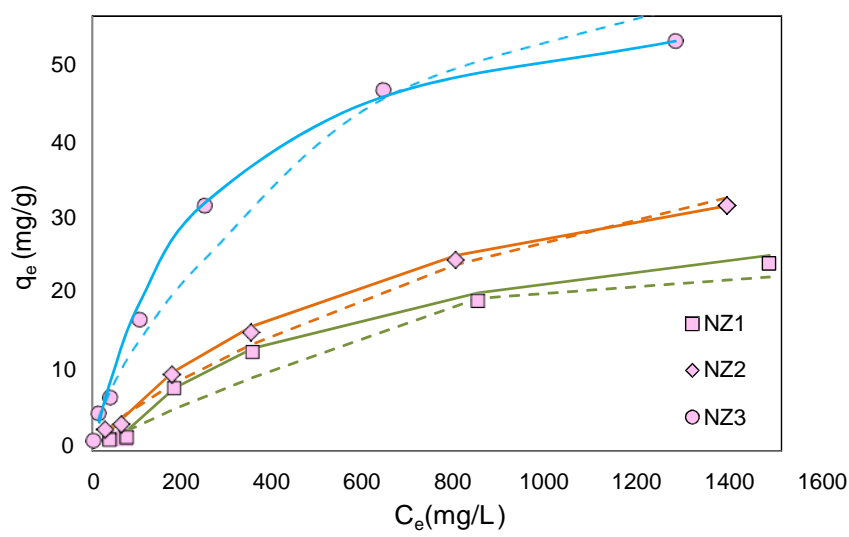

Figure 3. Experimental and theoretical equilibrium isotherms for ammonium removal by natural zeolites NZ1, NZ2 and NZ3 for a phase ratio of $0.2 \mathrm{~g} \mathrm{NZ}$ and $25 \mathrm{~mL}$ of aqueous solution at room temperature $22^{\circ} \pm 1$. (Dots: experimental data, line: the Langmuir predicted values, dashed line: the Freundlich predicted values.)

Table 4. Desorption efficiency of ammonium loaded NZs using $\mathrm{NaOH}, \mathrm{NaCl}$ and mixtures $\mathrm{NaOH} / \mathrm{NaCl}$ with aqueous solutions to zeolite ratios of $25 \mathrm{~mL}$ per $1.2 \mathrm{~g}$ at room temperature $22^{\circ} \mathrm{C}$

\begin{tabular}{|lccc|} 
& $\begin{array}{c}\text { NZ1 } \\
\text { EX(\%) }\end{array}$ & $\begin{array}{c}\text { NZ2 } \\
\text { EX(\%) }\end{array}$ & $\begin{array}{c}\text { NZ3 } \\
\text { EX(\%) }\end{array}$ \\
\hline $0.02 \mathrm{~mol} \mathrm{~L}^{-1} \mathrm{NaOH}$ & $94 \pm 3$ & $97 \pm 3$ & $88 \pm 2$ \\
$0.1 \mathrm{~mol} \mathrm{~L}^{-1} \mathrm{NaCl}$ & $89 \pm 4$ & $96 \pm 2$ & $89 \pm 4$ \\
$0.02 \mathrm{~mol} \mathrm{~L}^{-1} \mathrm{NaOH} / 0,1 \mathrm{~mol} \mathrm{~L}^{-1} \mathrm{NaCl}$ & $97 \pm 2$ & $98 \pm 1$ & $92 \pm 5$ \\
\hline
\end{tabular}

Samples were dried at low temperature to avoid losses of soluble forms of ammonium as $\mathrm{NH}_{3}$ (g). Similar results were found by Alshameri et al. ${ }^{41}$ and Guaya et al. ${ }^{15}$

\section{Zeolites reusability: ammonium desorption}

Results from desorption efficiency studies of ammonium from loaded zeolites using $\mathrm{NaOH}, \mathrm{NaCl}$ and mixtures $\mathrm{NaOH} / \mathrm{NaCl}$ are summarized in Table 4. Desorption was found to be a fast process (data not shown) and equilibrium was achieved in less than $20 \mathrm{~min}$. The regeneration tests showed that no significant loss of zeolite capacity was observed after five consecutive cycles. The rationale desorption process is that the reverse of the exchange reaction (Equation (11)) and the conversion of ammonium to ammonia could be possible by increasing the $\mathrm{pH}$ as it is described by reactions (12) and (13):

(i) Ion exchange reaction with sodium ions from $\mathrm{NaCl}$ :

$$
\mathrm{Z}_{4}^{-} \mathrm{NH}_{4}^{+}+\mathrm{Na}^{+} \leftrightarrow \mathrm{NH}_{4}^{+}+{\mathrm{Z}-\mathrm{Na}^{+}}^{+}
$$

(ii) Ammonium cónversion to $\mathrm{NH}_{3} \mathrm{n}$ basic media $\mathrm{NaOH}(\mathrm{pH}>12)$ :

$$
\mathrm{Z}^{-} \mathrm{NH}_{4}^{+}+\mathrm{Na}^{+}+\mathrm{OH}^{-} \leftrightarrow \mathrm{NH}_{3}+\mathrm{Z}^{-} \mathrm{Na}^{+}+\mathrm{H}_{2} \mathrm{O}
$$

Sodium rich solutions of $\mathrm{NaCl}$ and $\mathrm{NaOH}$ and a mixture of $\mathrm{NaCl} / \mathrm{NaOH}$ provided high desorption ratios with values above $90 \%$, for NZ1 and NZ2 samples and only recovery ratios between 85 and $95 \%$ were measured with NZ3. The use of sodium base brines as a means to regenerate $\mathrm{NaCl}$ is based on the selectivity order of natural zeolite among cations as reported by Sarioglu ${ }^{25}$ with the following sequence

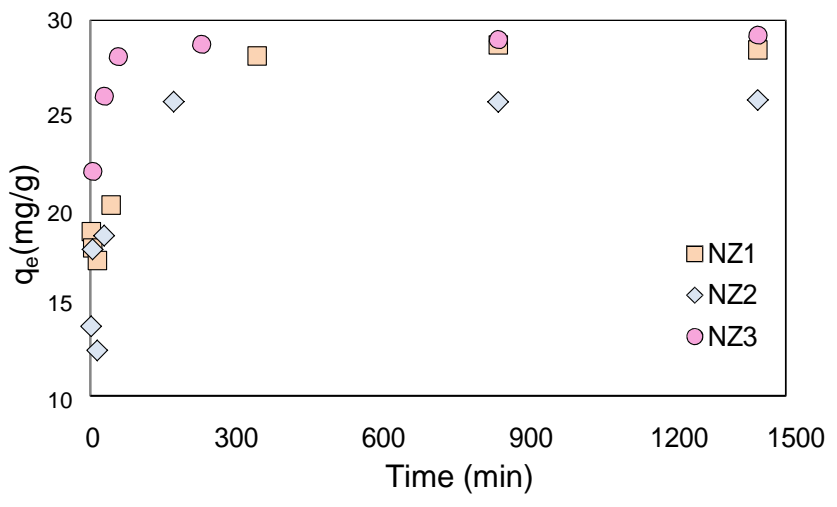

Figure 4. Influence of contact time on $\mathrm{NH}_{4}^{+}$removal sorption capacity of natural zeolites NZ1 $\left(q_{m} 19.4 \pm 0.6\right), \mathrm{NZ2}\left(q_{m} 23.9 \pm 0.8\right)$, and NZ3 $\left(q_{m}\right.$ $35.1 \pm 1.1$ ), for a solid -liquid ratio $0.2 \mathrm{~g}$ of zeolite and volume of $25 \mathrm{~mL}$ for an initial concentration of $864 \mathrm{mgNH}_{4} \mathrm{~L}^{-1}$ and $\mathrm{a} \mathrm{pH}$ of $7.7 \pm 0.3$.

\section{Ammonium sorption kinetics of powder zeolites in stirred} reactors

Ammonium sorption kinetic data $\left(Q_{t}\right.$ versus time) for $N Z$ zeolites are shown in Fig. 4. The ammonium sorption rates are comparable with other natural and synthetic zeolites demonstrating a very fast sorption step where more than $60 \%$ of the equilibrium attainment $(X(t)=0.60)$ is reached in less than $10 \mathrm{~min}$ followed by a slower sorption step controlled by a typical particle diffusion profile as encountered in most of the polymeric ion-exchange resins. ${ }^{37,51}$ Sorption profiles for the three zeolites show the typical behavior of a sorption material where the solid surface plays an important role. lon-exchange sites are distributed along the microporous structure and then diffusion processes are the rate determining step.

Comparing zeolites samples NZ1 and NZ2 need high times to reach equilibrium (60 min for Xt $>0.95$ ), while for NZ3 only $30 \mathrm{~min}$ were needed to reach $\mathrm{Xt}>0.95$. Analysis of the fractional equilibrium attainment functions $(F(X)=f(t))$ by using both HDM and SPM models indicated that sorption rate control of ammonium ions is particle diffusion. A first stage of $\mathrm{NH}_{4}{ }^{+}$diffusion from the solution to the external surface of zeolite is followed by a sorption stage along the zeolite internal surface. The linear regression analyses of the rate control equations are summarized in Table 5. The linear regression coefficients $\left(R^{2}\right)$ values are closer to 1 for the equations considering particle diffusion as rate determining step. Both models (HPDM and SPM) provided a good description of the experimental data as can be seen in supporting information (Fig. S4). Particle diffusion coefficients calculated ranged from 1.2 to $5.1 \times 10^{-12} \mathrm{~m}^{2} \mathrm{~s}^{-1}$. These values are consistent with the results reported for ammonium sorption on natural clinoptilolite at low initial ammonium concentrations and with diffusion coefficients determined on the removal of heavy metals by natural zeolites. ${ }^{39}$

$$
62 \mathrm{~K}^{+}>\mathrm{NH}_{4}^{+}>\mathrm{Na}^{+}>\mathrm{Ca}^{2+}>\mathrm{Fe}^{3+}>\mathrm{Al}^{3+}>\mathrm{Mg}^{2+} \text {. }
$$

Techno

logical

evalua

tion of

Yemeni

NZ1,

NZ2

and

NZ3

zeolite

sas

sorben 

ammonium up to 50-100 $\mathrm{mg} \mathrm{L}^{-1}$; and (c) side streams generated in the 119 sludge anaerobic reactor with concentrations of ammonia between $400 \quad 120$ $\begin{array}{ll}\text { and } 1600 \mathrm{mgNH}_{4} \mathrm{~L}^{-1} \text {. The applicability of } & 121\end{array}$ 
that have diroct implicatione for tho romoval of nhocohat

Table 5. Results of the kinetic data analysis for ammonium sorption by powder natural Yemeni zeolites (NZ1, NZ2, NZ3) in stirred tanks using both HPDM and SPM models

\begin{tabular}{|c|c|c|c|c|c|c|c|c|c|c|}
\hline & \multicolumn{4}{|c|}{ HPDM } & \multicolumn{6}{|c|}{ SPM } \\
\hline & \multicolumn{2}{|c|}{$\ln \left(1 x^{2}\right)$} & \multicolumn{2}{|c|}{$\ln (1 X)$} & \multicolumn{2}{|c|}{$x$} & \multicolumn{2}{|c|}{$\left[33(1 X)^{2 / 3} 2 X\right]$} & \multicolumn{2}{|c|}{$\left[1(1 X)^{1 / 3}\right]$} \\
\hline & $\mathrm{R}^{2}$ & $D_{f}\left(m^{2} s^{1}\right)$ & $\mathrm{R}^{2}$ & $D_{p}\left(m^{2} s^{1}\right)$ & $R^{2}$ & $\mathrm{~K}_{\mathrm{F}}\left(\mathrm{m} \mathrm{s}^{1}\right)$ & $\mathrm{R}^{2}$ & $D_{p}\left(m^{2} s^{1}\right)$ & $\mathrm{R}^{2}$ & $\mathrm{k}_{\mathrm{s}}\left(\mathrm{m} \mathrm{s}^{1}\right)$ \\
\hline NZ1 & 0.99 & $1.2410^{-12}$ & 0.79 & $1.1810^{-10}$ & 0.71 & $2.410^{-11}$ & 0.98 & $4.010^{-12}$ & 0.93 & $2.610^{-13}$ \\
\hline NZ2 & 0.96 & $2.110^{-12}$ & 0.86 & $5.810^{-10}$ & 0.73 & $3.710^{-11}$ & 0.96 & $3.010^{-12}$ & 0.82 & $2.210^{-13}$ \\
\hline NZ3 & 0.93 & $5.110^{-12}$ & 0.91 & $5.410^{-10}$ & 0.64 & $4.110^{-11}$ & 0.92 & $6.010^{-12}$ & 0.84 & $2.810^{-13}$ \\
\hline
\end{tabular}

the evaluated Yemeni zeolite samples was evaluated in terms of removal capacity and the treated effluent residual values achieved under these conditions were further compared with published data for natural zeolites. Table S2 summarizes both ammonium sorption and desorption equilibrium parameters.

By using the Langmuir or Freundlich isotherms theoretical predictions plotted for comparison are shown in Fig. 5 for effluents with high concentration of ammonium (from 100 to $1600 \mathrm{mgNH}_{4}$ $\mathrm{L}^{-1}$ ), effluents with medium ammonium concentrations (from 10 to $100 \mathrm{mgNH}_{4} \mathrm{~L}^{-1}$ ) and effluents with low ammonium concentrations (from 1 to $10 \mathrm{mgNH}_{4} \mathrm{~L}^{-1}$ ). It should be mentioned that in most cases (Table S2) the $\mathrm{pH}$ used in the experimental studies was not reported and in most cases the sorption isotherms were not carried out at constant $\mathrm{pH}$ values. Experiments conducted with NZ1, $\mathrm{NZ2}$ and NZ3 were carried out at $\mathrm{pH} 8$.

Comparison of isotherms in the three ranges of ammonium concentration indicates that the sorption capacity evaluated for NZ3 was up to two times higher than those reported for the other natural zeolites. In addition, the sorption capacity of NZ1 sample was similar to the highest values reported for the different zeolites evaluated. The better performance of NZ3 sample could be associated with the higher content of clinoptinolite and mordenite and also the presence of heulandites. The sample is also characterized by the presence of higher content of iron oxide.

The capacity to reduce the ammonium concentration to the target values as defined by most of the Environmental Regulation agencies (e.g. $15 \mathrm{mg} \mathrm{NH}_{4} \mathrm{~L}^{-1}$ for treated water to be discharged to water bodies or $1 \mathrm{mgNH}_{4} \mathrm{~L}^{-1}$ according to coming regulations) as a function of the zeolite dose is shown in Fig. 6. The ammonium residual values decreased with the increase of the dose. For zeolites NZ1 and NZ2, a reduction of the concentration respectively from 77 to $3 \mathrm{mgNH}_{4} \mathrm{~L}^{-1}$ and from 91 to $4.3 \mathrm{mgNH}_{4} \mathrm{~L}^{-1}$ was achieved for zeolite doses of $40 \mathrm{gNZ} \mathrm{L}^{-1}$. However, for NZ3, which showed a high sorption capacity at higher ammonium concentrations (see Fig. 3 and Table 3), under the low concentration range demonstrated higher ammonium residual concentrations (14 $\mathrm{mg} \mathrm{L}^{-1}$ for a $40 \mathrm{gNZ} \mathrm{L}^{-1}$ dose). Thus, the NZ tested demonstrated sufficient efficiency to remove ammonium up to the $15 \mathrm{mg} \mathrm{L}^{-1}$ threshold in the final effluent. But if the target value to achieve in the final effluent is $1 \mathrm{mg} \mathrm{L}^{-1}$, then it invariably dictates the need for an increase of the zeolite dosage.

A distinctive behaviour of NZ3 on reaching permissible levels for ammonium in comparison with NZ1 and NZ2 has been observed although having slightly higher ammonium sorption capacity. These differences could be associated with the effect of other cations present in the waste water $(\mathrm{Na}, \mathrm{Ca}, \mathrm{Mg}, \mathrm{K})$ influencing the sorption capacity in comparison with the model solutions. It must be noted that NZ3 has a higher content of Ca and Fe oxides
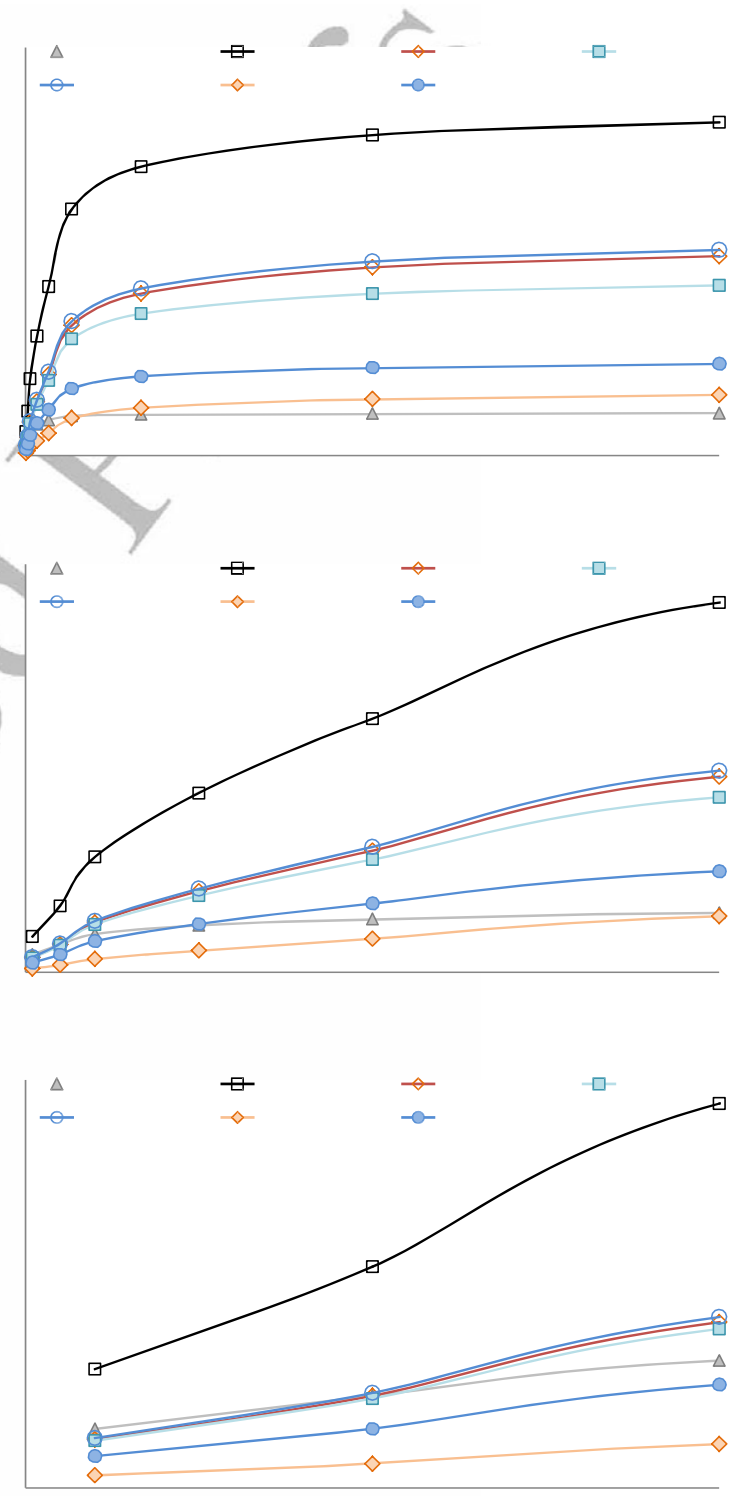
udy Slovalian NZ Iranian NZ Chineese NZ

8

6

4

4

2
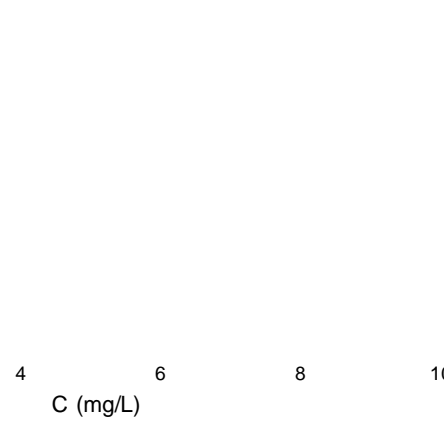

Figure 5. Comparison of isotherms for Yemeni natural zeolites (NZ1, NZ2 and NZ3) and for natural zeolites from Australia, China, Iran and Slovakia (properties and isotherm values are summarized in Table S2). Solid lines were calculated using the Langmuir or Freundlich constant collected in Table S2).








Figure 6. Variation of the residual ammonium concentration $\left(C_{e}\left(\mathrm{mg} \mathrm{L}^{-1}\right)\right)$ in solution as a function of the zeolite doses $\left(\mathrm{gZ} \mathrm{L}^{-1}\right)$. Solid lines described the discharge limits defined by theEC1991 on treated waste water limits for ammonium and solid line describe the expected new regulations. Volume was $864 \mathrm{mgN}-\mathrm{NH}_{4} \mathrm{~L}^{-1}$ and a pH of $7.6 \pm 0.2$ (DL: discharge limit).

(present in waste water) via complexation with < $\mathrm{FeOH}$ groups or formation of Ca-phosphates. Values of phosphate removal were not included in the scope of the work but the removal efficiency of NZ3 was reported to be higher than that of NZ1 and NZ2, and it may be postulated that this co-removal mechanism affected the ammonium removal.

\section{CONCLUSION}

The mineralogical characterization of three natural zeolites (NZ1, NZ2, NZ3) collected from different regions of Yemen indicated that clinoptilolite and mordenite were the major components of NZ1 and NZ2, but small amounts of other crystalline phases like quartz, feldspars and unaltered glass were also detected. For NZ3, in addition to clinoptilolite, mordénite some small amounts of heulandite, quartz and feldspar was also detected.

The three zeolite samples provided high ammonium sorption capacities for concentrated ammonium streams of 27 to 51 $\mathrm{mgNH}_{4} \mathrm{~g}^{-1}$ at $\mathrm{pH}$ values of $8.0 \pm 0.2$. Sample NZ3, with the highest $\mathrm{CaO}(\mathrm{s})$ and $\mathrm{Fe}_{2} \mathrm{O}_{3}(\mathrm{~s})$ contents showed the highest sorption capacities among the three studied zeolites; and its maximum sorption capacity was also recorded to be higher than those reported for other natural zeolites in the literature. Loaded zeolites were efficiently regenerated using $\mathrm{NaOH}$ and $\mathrm{NaOH} / \mathrm{NaCl}$ brines $\left(0.1 \mathrm{~mol} \mathrm{~L}^{-1}\right)$. Recovery of ammonia from regeneration solutions, by using for example air-striping or liquid-liquid contactors will provide the possibility of reusing the stripping solutions for several cycles. The number of cycles will depend on the accumulation of cations as $\mathrm{Ca}$ (II) and $\mathrm{Mg}$ (II) or dissolved organic matter.

The ammonium sorption kinetics of the powdered zeolite samples was controlled by particle diffusion and was well described by the HPDM and SPM models. Faster kinetics was exhibited by NZ3 in comparison with those of the two other studied zeolites. Comparison of the kinetic data for the characterized Yemeni zeolite samples with published results for other natural and synthetic zeolites demonstrate their higher performance, which could be used in stirred tank applications. Doses of $40 \mathrm{gNZ} \mathrm{L}^{-1}$ was found to be from diluted ammonium streams generated in high rate activated sludge stages and below $10 \mathrm{mgNH}_{4} \mathrm{~L}^{-1}$ from concentrated ammonium streams generated in side streams of anaerobic digestion of sewage sludge. of aqueous solution was $25 \mathrm{~mL}$ and the initial ammonium concentration suitable to achieve ammonium residual levels below $1 \mathrm{mgNH}_{4} \mathrm{~L}^{-1}$

\section{ACKNOWLEDGEMENTS}

This study has been supported by the ZERODISCHARGE project (CTQ2011-26799) and the Waste2Product project (CTM2014-57302-R) financed by Ministry of Science and Innovation (MINECO, Spain) and the Catalan government (project ref. 2014SGR050). I gratefully acknowledge the financial support given to this study by the Tunisian Ministry of Higher Education and Scientific Research, and finally, my thanks to I. Lopez (Laboratory of Electronic Microscopy, Universitat Politècnica de Catalunya) for the FESEM analysis.

\section{Supporting Information}

Supporting information may be found in the online version of this article.

\section{REFERENCES}

1 Maranon E, Ulmanu M, Fernandez Y, et al., Removal of ammonium from aqueous solutions with volcanic tuff. J Hazard Mater 137:1402-1409 (2006).

2 Huang $H$, Xiao $X$, Yan $B$ and Yang $L$, Ammonium removal from aqueous solutions by using natural Chinese (Chende) zeolite as adsorbent. $\mathrm{J}$ Hazard Mater 175:247-252 (2010).

3 Zheng H, Han L, Ma H, Zheng Y, Zhang H, Liu D and Liang S, Adsorption characteristics of ammonium ion by zeolite 13X. J Hazard Mater 158:577-584 (2008).

4 Ahn YH, Sustainable nitrogen elimination biotechnologies: a review. Process Biochem 41:1709-1721 (2006).

5 Blackburne R, Yuan Z and Keller J, Demonstration of nitrogen removal via nitrite in a sequencing batch reactor treating domestic wastewater. Water Res 42:2166-2176 (2008).

6 Jimenez J, Miller M, Bott C, Murthy S, De Clippeleir H and Wett B, High-rateactivated sludge system for carbon management - evaluation of crucial process mechanisms and design parameters. Water Res 87:476-482 (2015).

7 Zhao W, Ting YP, Chen JP, Xing CH and Shi SQ, Advanced primary treatment of waste water using a bio-flocculation-absorption sedimentation process. Acta Biotechnol 20:53-64 (2000).

8 Hermassi M, Valderrama C, Gibert O, Moreno N, Querol X, Batis NH and Cortina JL, Recovery of nutrients (N-P-K) from potassium-rich sludge anaerobic digestion side-streams by integration of a hybrid sorption-membrane ultrafiltration process: use of powder reactive sorbents as nutrient carriers. Sci Total Environ 599-600:422-430 (2017).

9 You X, Valderrama C and Cortina JL, Simultaneous recovery of ammonium and phosphate from simulated treated wastewater effluents by activated calcium and magnesium zeolites. Chem Technol Biotechnol (2017).

10 Zhang X, Dong L, Liang Y, He Y, ZhangY and Zhang J, Autotrophic nitrogen removal from domestic sewage in MBR-CANON system and the biodiversity of functional microbes. Bioresource Technol 150:113-120 (2013).

11 Mezohegyi G, Bilad MR and Ivo FJ, Vankelecom, direct sewage upconcentration by submerged aerated and vibrated membranes. Bioresource Technol 118:1-7 (2012).

12 Diamantis V, Eftaxias A, Bundervoet B and Verstraete W, Performance of the biosorptive activated sludge (BAS) as pre-treatment to UF (2014).

13 Zubair Ahmed, Jinwoo Cho, Byung-Ran Lim, Kyung-Guen Song and Kyu-Hong Ahnm, Effects of sludge retention time on membrane fouling and microbial community structure in a membrane bioreactor. $J$ Membrane Sci 287:211-218 (2007).

14 Sprynskyy M, Lebedynets M, Terzyk AP, Kowalczyk P, Namiesnik J and Buszewski B, Ammonium sorption from aqueous solutions by the natural zeolite. Transcarpathianclinoptilolite studied under dynamic conditions. J Colloid Interface Sci 284:408-415 (2005).

15 Guaya D, Valderrama C, Farran A, Armijos C and Cortina JL, Simultaneous phosphate and ammonium removal from aqueous solution by a hydrated aluminum oxide modified natural zeolite. Chem Eng J 271:204-213 (2015).

16 Thornton $A$, Pearce $P$ and Parsons SA, Ammonium removal from solution using ion exchange on to MesoLite, an equilibrium study. $J$ Hazard Mater 147:883-889 (2007). for decentralized wastewater reuse. Bioresource Technol 156:314-321 
17 Hermassi M, Valderrama C, Gibert O, Moreno N, Font O, Querol $\mathrm{X}$, et al., Integration of powdered ca-activated zeolites in a hybrid sorption-membrane ultrafiltration process for phosphate recovery. Ind Eng Chem Res 55:6204-6212 (2016).

18 Karapınar N, Application of natural zeolite for phosphorus and ammonium removal from aqueous solutions. J Hazard Mater 170:1186-1191

19 (2009). tion of a Chilean natural zeolite. Int J Miner Process 75:21-29 (2005).

20 Singer PA, Salamanca-Buentello F and Daar AS, Harnessing nanotechnology to improve global equity. Issues Sci Technol 21:57-64 (2005).

21 Elaiopoulos K, Perraki T and Grigoropoulou E, Mineralogical study and porosimetry measurements of zeolites from Scaloma area, Thrace, Greece. Micropor Mesopor Mater 112:441 (2008).

22 Jorgersen TC and Wetherley LR, Ammonium removal from wastewater by ion exchange in the presence of organic contaminants. Water Res 37:1723-1728 (2003).

23 Wang $\mathrm{YF}$, Lin $\mathrm{F}$ and Pang $\mathrm{WQ}$, Ammonium exchange in aqueous solution using Chinese natural clinoptilolite and modified zeolite J Hazard Mater 142:160-164 (2007).

24 Nguyen ML and Tanner CC, Ammonium removal from waste waters using natural New Zealand zeolites. New Zealand J Agric Res 41:427-446 (1998).

25 Sarioglu M, Removal of ammonium from municipal waste water using natural Turkish (Dogantepe) zeolite. Sep Purif Technol 41:1-11 (2005).

26 Shoumkova A, Zeolites for water and wastewater treatment, an overview. Research Bulletin of the Australian Institute of High Energetic Materials, Special Issue on Global Fresh Water Shortage (2) 10-70 (2011).

27 Thornton A, Pearce $P$ and Parsons SA, Ammonium removal from solution using ion exchange on to MesoLite, an equilibrium study. $\mathrm{J}$ Hazard Mater 147:883-889 (2007).

28 Filippidis A, Apostolidis N, Filippidis S and Paragios I, Purification of industrial and urban wastewaters, production of odorless and cohesive zeolite-sewage sludge, using hellenic natural zeolite. Proc 2nd Intern Conf on Small and Decentralized Water and Wastewater Treatment Plants, Skiathos, 403-408 (2008).

29 Ivanova E, Karsheva M and Koumanova B, Adsorption of ammonium ions onto natural zeolite. J Univ Chem Technol Metall 45:295-302 (2010).

30 Wanga $S$ and Peng $Y$, Natural zeolites as effective adsorbents in water and wastewater treatment. Chem Eng J 156:11-24 (2010).

31 Alpat SK, Ozbayrak O, Alpat S and Akcay H, The adsorption kinetics and removal of cationic dye, Toluidine Blue $\mathrm{O}$, fromaqueous solution with Turkish zeolite. J Hazard Mater 151:213-220 (2008).

32 Ashrafizadeh SN, Khorasani Z and Gorjiara M, Ammonia removal from aqueous solutions by Iranian natural zeolite. Sep Sci Technol 43:960-978 (2008).

33 Millar GJ, Winnett A, Thompson T and Couperthwaite SJ, Equilibrium studies of ammonium exchange with Australian natural zeolites. J Water Process Eng 9:47-57 (2016).

34 Zeolite in Yemen, Exploration and mining in Yemen by Yemen Geological Survey and Mineral Resources Board, Schultz Grafisk, Yemen, (2009)

35 Zebardast HR, Pawlik M, Rogak S and Asselin E, Potentiometric titration of hematite and magnetite at elevated temperatures using a ZrO2-based pH probe. Colloids Surf A 444:144-152 (2014).

36 Hlaway J, Vigh Gy, Olaszi V and Inczedy J, Investigations on natural Hungarian zeolite for ammonium removal. Water Res 16:417-420 (1982).
37 Zaghouane-Boudiaf $\mathrm{H}$ and Boutahala $\mathrm{M}$, Adsorption of 2, 4, 5trichlorophenol by organo-montmorillonites from aqueous solutions: kinetics and equilibrium studies. Chem Eng J 170:120 - 126 (2011).

38 Ostroomov M, Mineralogical study from New Mexican deposits. App Cl Sci 55:27-35 (2012).

39 Alshameri A, An investigation into the adsorption removal of ammonium by salt activated Chinese (Hulaodu) natural zeolite: Kinetics, isotherms, and thermodynamics. JTaiwan Inst of Chem Eng 45:554 - 564 (2014).

40 Favvas EP, Tsanaktsidis CG, Sapalidis AA, Tzilantonis GT, Papageorgiou SK and Mitropoulos ACh, Clinoptilolite, a natural zeolite material: structural characterization and performance evaluation on its dehydration properties of hydrocarbon-based fuels. Micropor Mesopor Mater 225:385-391 (2016).

41 Alshameri A, Ibrahim A, Assabri AM, Lei X, Wang $\mathrm{H}$ and Yan Ch, The investigation into the ammonium removal performance of Yemeni natural zeolite: Modification, ion exchange mechanism, and thermodynamics. Powder Technol 258:20-31 (2014).

42 Hermassi M, Valderrama C, Moreno N, Font O, Querol X, Batis NH and Cortina JL, Fly ash as reactive sorbent for phosphate removal from treated waste water as a potential slow release fertilizer. J Environ Chem Eng 5:160-169 (2017).

43 You X, Farran A, Guaya D, Valderrama C, Soldatov V and Cortina JL, Phosphate removal from aqueous solutions using a hybrid fibrous exchanger containing hydrated ferric oxide nanoparticles. J Environ Chem Eng 4:388-397 (2016).

44 Kosmulski $\mathrm{M}$, $\mathrm{pH}$-dependent surface charging and points of zero charge. IV. Update and new approach. J Colloid Interface Sci 337:439-448 (2009)

45 Kosmulski $\mathrm{M}$, The $\mathrm{pH}$-dependent surface charging and points of zero chargeV. Update. J Colloid Interface Sci 353:1-15 (2011).

46 Guaya D, Valderrama C, Farran A and Cortina JL, Modification of a natural zeolite with $\mathrm{Fe}$ (III) for simultaneous phosphate and ammonium removal from aqueous solutions. J Chem Technol Biotechnol 91:1737-1746 (2016).

47 Alshmari A, et al., Enhancement of phosphate removal from water by $\mathrm{TiO}_{2} /$ Yameni natural zeolite: preparation, characterization and thermodynamic. Micropor Mesopor Mater 196:145-157 (2014).

48 Colella C, Natural zeolites and environment, in Introduction to Zeolite Science and Practice, 3rd revised edn, ějka JC, van Bekkum H, Corma A and Scho F 9th (eds). Studies Surf Sci Catal 168:999-1035 (2007).

49 Moussavi G, Talebi S, Farrokhi M and Sabouti RM, The investigation of mechanism, kinetic and isotherm of ammonia and humic acid coadsorption onto natural zeolite. Chem Eng J 171:1159-169 (2011).

50 Mosgawa W, The relation between structure and vibrational spectra of natural zeolites. J Mol Struct 596:129-137 (2001).

51 Widiastuti $\mathrm{N}, \mathrm{Wu} \mathrm{H}$, Ang HM and Zhang D, Removal of ammonium from greywater using natural zeolite. Desalination 277:15-23 (2011).

52 Lin L, Lei Z, Wang L, Liu X, Zhang Y, Wan C, et al., Adsorption mechanisms of high-levels of ammonium onto natural and $\mathrm{NaCl}$-modified zeolites. Sep Purif Technol 103:15-20 (2013).

53 Malekian R, Abedi-Koupai J, Eslamian SS, Mousavi SF, Abbaspour KC and Afyuni $\mathrm{M}$, lon-exchange process for ammonium removal and release using natural Iranian zeolite. Appl Clay Sci 51:323-329 (2011).

54 Ates A and Akgül G, Modification of natural zeolite with $\mathrm{NaOH}$ for removal of manganese in drinking water. Powder Technol 287:285-291 (2016).

63

64

65

66

67

68

69

70

71

72

73

74

75

76

77

78

79

80

81

82

83

84 